\title{
A clínica como poiética
}

\section{Clinic as a poietic}

\section{Mônica Botelho Alvim*}

Universidade Federal do Rio de Janeiro - UFRJ, Rio de Janeiro, RJ, Brasil

\begin{abstract}
RESUMO
Um dos temas fundamentais na clínica diz respeito à produção de sentido. Quando Merleau-Ponty enfatiza a noção de carne, propõe uma espécie de passividade do eu ao campo, a um ser bruto que comporta eu e outro, cultura, historicidade, temporalidade. Afirma a necessidade de passar da erlebnisse (vivência) à stiftung (instituição), colocando acento num tipo de produção de sentido que é gênese espontânea, diferenciação, criação a partir da diferença. Neste trabalho discutimos a clínica da Gestalt-terapia em diálogo com essas propostas e as questões contemporâneas, para propor a clínica como lugar de criação, que visa permitir o nascimento espontâneo do sentido como fala falante e desviante; a gênese do sentido como instituição que nos garante o pertencimento com o outro a um mesmo mundo. É nesse sentido que podemos pensar em uma ética da criação na diferença - uma clínica como poiética.
\end{abstract}

Palavras-chave: Gestalt-terapia, Merleau-Ponty, Instituição, Psicologia clínica, Corpo.

\begin{abstract}
A key theme of the clinic relates to the production of meaning. When Merleau-Ponty emphasizes the notion of flesh, proposes a kind of passivity of the self to the field, a brute being who holds self and other, culture, history, temporality. Affirms the need to move from Erlebnisse (experience) to Stiftung (institution), placing emphasis on a kind of sense produced by spontaneous genesis, differentiation, creation from the difference. We discuss the clinical gestalt therapy in dialogue with these proposals and contemporary issues, to propose the clinic as a place of creation, designed to allow spontaneous birth of meaning as deviant speech; the genesis of the sense as an institution guarantees belonging with the other to the same world. In this sense we can think of an ethics of creation from the difference - clinic as a poietic
\end{abstract}

Keywords: Gestalt-Therapy, Merleau-Ponty, institution, clinical psychology, body.

\section{Introdução}

Marginal é quem escreve à margem, deixando branca a página para que a paisagem passe 
A poesia de Leminski nos faz um convite. Escrever à margem deixando a página em branco para a passagem da paisagem. Barry Stevens, gestalt-terapeuta, eternizou a imagem de um terapeuta marginal - aquele que escreve à margem - no título "Não apresse o rio, ele corre sozinho". O que está implicado nessa imagem? Ficar à margem do rio que corre, escrever à margem, deixar a paisagem passar ou o rio correr. Esperar. Respeitar o ritmo. Não apressar. Deixar espaço em branco. Não preencher.

O convite de ambos é para um trabalho - do terapeuta e do poeta que confiando na vida (como vir-a-ser), concebe o fluxo e o vazio como espaço-tempo de poder ser. Nesse trabalho, o olhar que admira e espera que algo se faça, possa ser, exige abertura e não-fixação, presença e não-representação.

Está em jogo aqui o tema da produção de sentido, tema fundamental na clínica, um espaço de possibilidade de ressignificação da existência. Compreendo a clínica como um campo de experiência com o outro que faz brotar sentidos a partir da expressão e do diálogo. Espaço de instituição que vejo, aproximando-me do ponto de vista de Merleau-Ponty, como um processo de nascimento, "operação que é ao mesmo tempo recuperação e superação de significações anteriores e apelo a novas criações de sentido" (DUPOND, 2010, p. 38). Um processo reversível entre o arqueológico e o teleológico, passado e futuro, um ecoando no outro, aqui-agora.

\section{Experiência e expressão}

A expressão é gesticulação corporal, de acordo com Merleau-Ponty. Longe de ser a colocação no mundo como objetividade de algo já pronto no interior como subjetividade, a expressão envolve um movimento reversível de sair de si e entrar em si, movimento ekstático, "ímpeto ou arrebatamento de nosso corpo em direção a algo que, mesmo não diferindo de nossa própria temporalidade, não nos faculta coincidir conosco, exigindo de nós, a cada experiência, um novo recomeço" (MÜLLER, 2001, p. 285). Merleau-Ponty, nos rastros de Husserl, entende que é o corpo sensível que nos dá o sentido da possibilidade, do Ich cann (eu posso). Propõe a experiência como expressão e fala, gesticul-ação corporal em situação com o mundo, síntese temporal, trabalho do corpo, práxis que é gênese de sentido, uma praktognosia. O sentido se faz enquanto expressão. Assim Merleau-Ponty (1994) define o que chama "milagre da expressão" ( $p$. 268): fazer a significação existir como coisa no mundo, presença, 
emblema, corpo (p. 247). A potência de expressão, ele afirma, é bem conhecida na arte. "A expressão estética confere a existência em si àquilo que exprime, instala-o na natureza como uma coisa percebida acessível a todos (...) a operação expressiva realiza ou efetua a significação e não se limita a traduzi-la" (op.cit., p.248).

É também na direção da experiência como expressão que Lygia Clark $^{1}$ busca aproximar arte e vida. Trabalha para transformar 0 espaço da obra de arte em um espaço orgânico expressional. Convidando o espectador a participar ativamente da obra, transverte o espaço da arte em um espaço-tempo. Redireciona as relações do espectador com a obra de arte de um lugar de contemplação para outro de um ato corporal, ou seja, síntese temporal realizada pelo corpo: a experiência expressiva, ato corporal que institui um espaçotempo, faz a obra de arte. Marginal, a artista deixa em branco o espaço, entregando ao participante, antes espectador, a autoria, o poder-ser.

Definindo a psicologia como o estudo da operação da fronteira de contato no campo organismo/ambiente, a Gestalt-Terapia enfatiza a experiência, operação criadora e expressiva diante da tensão da diferença com o ambiente. Ao definir self como um sistema de contatos, promove um duplo movimento do eu: deslocado do interior do psiquismo para o campo, ele é descentralizado; perdendo o estatuto de pura representação, o eu, insubstancial, é compreendido como um processo de desdobramento temporal, espontaneidade expressiva e criadora.

Considerando a neurose um estado de distanciamento do corpo e da experiência, dicotomização mente-corpo e corpo-mundo que implica em fixação, rigidez de formas e impossibilidade de criar, a gestaltterapia propõe uma clínica que visa restituir plasticidade e fluidez na formação de formas, retomar o livre fluxo de awareness. Definida por Robine (2006) como conhecimento imediato e implícito do campo, a awareness é experiência temporal que envolve sentir, excitamento e formação de gestalten. Dimensão pré-reflexiva, o sentir é pathos de abertura, entrega ao campo e ao diferente que me afeta, convoca e anima, fazendo nascer um excitamento e um movimento corporal espontaneamente orientado ao futuro que se avizinha e se liga ao passado, fundo habitual que sustenta a formação de gestalt. Desse modo, a Gestalt-terapia, menos que uma teoria da personalidade é uma teoria da criação e expressão, uma terapia da formação de formas: movimento do presente para o futuro que não prescinde do passado, ação- atividade, paixão - passividade (pathos). 


\section{Corpo e intercorporeidade}

A fenomenologia de Husserl em sua última fase, tal como compreendida por Merleau-Ponty e transmitida em seus cursos sobre a natureza (MERLEAU-PONTY, 2000n), afirma o corpo como originário. $O$ mundo das idealizações é construído sobre um mundo pré-reflexivo em que o papel do corpo é o de operar uma síntese de transição que permita compreender o mundo de dentro dele, numa relação com as coisas do mundo que se dê pelos movimentos do corpo que avança e recua, dá voltas, reúne perspectivas. "Eu organizo com o meu corpo uma compreensão do mundo", afirma Merleau-Ponty (2000n, p. 122). Tal compreensão não é dada por uma consciência reflexiva, mas é sentimento de poder (possibilidade) dado pela inserção em um mesmo campo, "campo onde se localizam minhas sensações" (MERLEAU-PONTY, 2000n, p. 122).

O corpo é excitável, capacidade de sentir não como reação, mas como co-presença com as coisas. O sentir localiza-se, assim, no corpo-mundo, nesse campo ou situação aqui-agora. Tal consciência, dada pelo corpo, é "escorregadia, o sentimento de um poder" (op.cit). É na relação com outrem que me completo como existência objetiva, que passo de tal consciência escorregadia, desse sentimento de poder, a uma concretude da realização daquilo que apenas sinto. É vendo o outro ver o que vejo, movendo-se, como eu, em direção a algo, numa operação que, antes de reflexiva é estesiológica, que surge um eu como concretude no espaço e no tempo. Husserl, tal como afirma Merleau-Ponty (2000n, p. 125) propõe assim que a Einfülung (empatia) é uma operação corporal, "(...) a posição de um sujeito estesiológico. Eu não projeto no corpo de outrem um Eu penso, mas apercebo o corpo como percipiente antes de apercebê-lo como pensante".

Ao escolher o termo organismo e não sujeito ou pessoa, a GestaltTerapia marca o lugar do corpo na experiência no mundo. È nesse sentido que podemos falar de organismo como totalidade mentecorpo imbricada no mundo, numa relação que não tem produto ou produtor, atividade ou passividade absolutas, que Merleau-Ponty (2000n) denominou naturante-naturado e a Gestalt-terapia referese, em sua teoria do self, como modo médio de funcionamento ${ }^{2}$. 0 método da Gestalt-Terapia propõe concentrar-se na estrutura concreta da situação para restituir o brilho e o vigor da figura débil. 0 que significa uma figura débil? Que não há in-corporação, o fluxo de awareness está impedido e a excitação perdida como direção e moviment-ação. O terapeuta busca estabelecer uma relação com a situação a partir de seu corpo e de sua presença, assumindo a posição de um sujeito estesiológico, convidando, assim, o cliente ele mesmo a voltar-se para o corpo. Busca resgatar a relação de copresença. A espontaneidade do terapeuta distingue a Gestalt-Terapia, 
indicando que a relação terapêutica solicita, sobretudo, uma presença engajada que permita um encontro que seja experiência estética do campo, um campo de presença.

Merleau-Ponty, na última fase de seu trabalho, deixa o ponto de vista de um corpo-sujeito, para enfatizar a noção de carne, propondo assim uma espécie de passividade do eu ao campo, a um ser bruto que comporta eu e outro, cultura, historicidade, temporalidade. $\mathrm{O}$ filósofo critica a crença em uma subjetividade transparente a si mesma e um caráter constituinte da consciência e propõe um campo primordial, uma indiferenciação original de onde brota o sentido, o ser bruto, anterior a qualquer diferenciação em termos de subjetividade. Trata-se de uma dimensão sensível e passível apenas de compreensão corporal e de ser compartilhada por meio da experiência intercorporal.

Referimo-nos em Gestalt-Terapia a um id da situação (PERLS; HEFFERLINE; GOODMAN, 1997; ROBINE, 2006; ALVIM, 2007). Compreendo, a partir desse construto, que estamos voltados para a dimensão sensível e intercorporal do processo de contato que, na situação terapêutica, dá indícios da necessidade em dominância. A fonte do excitamento está no contato. Não está em alguma profundeza do eu, tampouco no estímulo do ambiente, mas na situação, nessa imbricação, entrecruzamento que conecta eu e outro, visível e invisível, singularidade e universalidade, fato e essência configurando uma estrutura, Ser em estado bruto (MERLEAU-PONTY, 2000). O trabalho psicoterápico, em nossa perspectiva, deve partir da exigência de sentido dada no diálogo e no contato, experiência de alteridade que é ao mesmo tempo diferença e identidade. Esse diálogo é, na perspectiva de Merleau-Ponty, intercorporeidade. Ao contrário de um diálogo que se dê em torno de uma reflexão, busca de constituição de sentido por uma consciência ativa, é um trabalho de instituição. Modo médio, passividade-atividade, co-presença, precisa dar-se inter corpos, partindo do id da situação, ou seja, isso que está aqui-agora, em estado bruto, em processo de diferenciação, visível em processo de fazer-se, emergindo de um fundo (carne) que é invisível, todavia presente e sensível.

Concebendo então o corpo como experiência originária, falamos de corpos vivos, vibrando diante do outro, movimentando a carne (MERLEAU-PONTY, 2000) que é também mundo. Carne, que trêmula, nos sustenta como um fundo no qual estamos apoiados e do qual brotamos como diferença. Partimos desse ponto para pensar no primeiro de alguns cenários necessários para compor nossa construção neste texto. 


\subsection{Cenário 1- Do corpo no mundo contemporâneo}

Como estão nossos corpos no mundo contemporâneo? Menos vibrantes: dormentes, an-estesiados, ou seja, sem estesis ou movimento. Menos totalidade: cindidos, tornados objetos submetidos à racionalidade ela própria moldada e controlada por padrões externos. Menos imbricados no mundo: fechados em nós como partes-extra-partes, mais e mais naturados, objetos feitos de fora, produzidos em série nos espelhos das academias, nas vitrines da moda, no jogo das imagens reais ou virtuais, que cooptam e banalizam a invenção transformando a criação em produto serializado, serial-killers dos corpos vibrantes. Uma espécie de morte em vida.

Como fazer frente a esse tipo de vida morta?

A morte de Cara de cavalo, um bandido do morro da Mangueira, em meados dos anos 60, movimentou Helio Oiticica na invenção de uma obra-homenagem, um de seus bólides, que nomeou Cara de cavalo. O mergulho na comunidade da Mangueira atraiu seu olhar para uma poética da ludicidade e da alegria do corpo que dança, da construção coletiva, da liberdade lúdica que implica o corpo-no-mundo-com-ooutro. Diante da revolta do próprio artista com a desigualdade social e os falsos valores "que pregam o bem-estar, a vida em família, mas que só funcionam para uma pequena minoria" (OITICICA, 1986, p. 82), o bordão que ecoava dele era "Seja marginal, seja herói". O heroísmo do marginal está em praticar uma "antimoral" (op.cit), situar-se à margem. A obra de Oiticica é um elogio ao herói solitário e morto por sua radical e trágica não-submissão à ordem instituída. Na obra-homenagem de Helio, há uma denúncia contra a miséria, a injustiça social, a repressão. E uma ode à subversão. "Estão como que justificadas todas as revoltas individuais contra valores e padrões estabelecidos", afirma (OITICICA, 1986, p. 81). O artista expressava na homenagem a Cara de cavalo sua crença absoluta na adesão do estético e do ético pela cola da criação e da transgressão. No limite da auto-destruição, estamos diante da morte como conseqüência (trágica) de uma radical tentativa de afirmação de vida.

Dialeticamente opostas, uma vida morta e uma morte viva nos convidam a pensar uma psicologia a serviço da restituição da vida. Que reacenda os corpos, quase sempre mortos-vivos encenando a tragédia da imagem simulacro. Uma psicologia que restitua o que há de heróico na transgressão. Que convide ao diálogo e ao coletivo como instância legítima de vida. Vida que cria, transgride e é legitimada nos olhares outros do coletivo.

A poesia, a terapia, a arte e a filosofia aqui trazidas, convergem na ênfase na experiência expressiva, na direção ao âmbito de um eu posso. Baseados na compreensão de que a criação é experiênciacorpo, trabalho de produção de sentidos, instituição, propõem um 
tipo de diálogo - do escritor com o leitor, do participante com a obra, do cliente com o terapeuta - que seja "invenção comum de verdade" (DUPOND, 2010, p. 31), processo que ultrapasse a alternativa entre passividade e atividade, fato e essência, natureza e cultura.

Tal diálogo envolve gesticulação corporal, expressão e linguagem, fala falante, palavras e gestos de um que convocam o outro pelas discrepâncias, lacunas, desvios e diferenças. Processos de descentramento e criação articulados por um diálogo intercorporal, como unidade básica da vida que se faz e refaz. Ao voltarmo-nos para a ampliação da capacidade de awareness, estamos baseados na proposta de que o fenômeno originário é a experiência, tal como compreende Merleau-Ponty em seus últimos escritos, quando radicaliza a idéia de que as essências estão subordinadas à experiência. Essências e fatos são inseparáveis, a experiência como variação e a essência como invariante são dimensões que não se pode separar. Para Merleau-Ponty, tal como afirma Dupond (2010, p. 25), "todo fato é internamente estruturado ou armado por uma essência selvagem, regra invisível da visibilidade, da generalidade ou do sentido".

$\mathrm{Na}$ neurose a experiência está soterrada pelos conceitos e idéias, falsas essências. O corpo, anestesiado e encouraçado (Wilhem Reich), docilizado e feito máquina (Michel Foucault), seja autômato ou sintomático, expressa e torna visível tensões e conflitos envolvidos nas relações com o mundo sócio-histórico. Na neurose há um impedimento do fluxo espontâneo do excitamento, em função desses conflitos.

Na situação terapêutica visamos, então, concentrarmo-nos no corpo sensível e nos sinais do excitamento que aponta para a direção daquilo que representa vitalidade, sinais que dão indícios da necessidade dominante, da força de vida, da essência, do sentido de ser. Aquilo que, de modo neurótico, está impedido, mas que não está morto.

No morto-vivo, decerto, ainda há vida, ainda que como um rasgo ou ponto, débil sinal que, muitas vezes como derradeira tentativa, leva alguém a buscar a terapia. Reconhecer esse sinal, gesticulação mínima, imagem quase toda borrada, requer um olhar aberto, distraidamente atento, que seja não intelectualidade, mas experiência estética, atitude que aqui chamamos marginal, atitude de espera, certa lentidão.

Diante da situação contemporânea pergunto se isso seria suficiente. Pergunto sobre a existência, no contexto atual, de fatores limitantes ou condicionantes da possibilidade de responder à exigência ekstática de um novo recomeço. Uma prática psicológica, compreendida em nossa perspectiva, se constrói e reconstrói em uma via de mão dupla, no mundo, precisa ser um tipo de práxis que produza gnose. Faz-se necessário dirigir nosso olhar para o mundo em sua dimensão 
sócio-histórica para prosseguir em nossa reflexão. Traçemos, então alguns outros cenários.

\subsection{Cenário 2: da psicologia tal como é vista no mundo contemporâneo}

Em nossos tempos a psicologia está afirmada como ciência e práxis. No imaginário social o psicólogo ocupa lugares distintos, dos quais destaco dois: o daquele que escuta, acolhe e compreende; e o do especialista que sabe. O primeiro ocupa o lugar que se tornou vazio no mundo da solidão e do individualismo onde ninguém escuta ninguém; o segundo corresponde à demanda pelo saber científico e objetivo de alguém que sabe o que eu não sei e vai me curar.

Os dois lugares não são excludentes e refletem um modo de pensar contemporâneo construído ao longo do desenvolvimento da psicologia. O primeiro reflete um modo de estar no mundo marcado por individualismo, onipotência e auto-referência que gera um movimento centrípeto na busca de uma subjetividade transparente a si mesma. O segundo lugar do psicólogo reflete a predominância de um tipo de lógica mecanicista e explicativo-causal, um pensamento analítico que diante do sofrimento busca causas, origens, explicações, esperando encontrar em um tipo de análise genéticoconstitutiva a cura para o sofrimento. Ambos conduzem ao indivíduo e ao psiquismo como instâncias legítimas do tratamento psicológico.

Mais que afirmada como práxis, há, em certas camadas da sociedade, uma psicologização da existência. Jacó-Vilela e Rodrigues (2004) discutem a divisão histórica da psicologia em duas vertentes: uma que compreende a psicologia necessariamente intrincada com o social e a vertente hegemônica, a psicológica, que acentua o indivíduo e a psyché e que, no máximo, inclui a sociedade como coadjuvante. Para essa vertente, "o social pode, em síntese, influenciar o psicológico, mas não o produz nem o fundamenta" (op.cit., p.217). As autoras discutem uma historiografia da psicologia no Brasil, mostrando que a origem dos "estudos sobre o homem" é marcada por discursos médicos que, "a posteriori serão reconhecidos como psicológicos" (op.cit., p.219). O modelo médico cientificista e da especialização se propaga na psicologia desenvolvida ao longo do século $\mathrm{XX}$, afirmando o indivíduo, seja na dimensão da interioridade, da consciência, do inconsciente, ou mesmo do comportamento (op.cit). Fato é que o psiquismo está na base e é o foco do trabalho clínico. A clínica inclui as relações com o outro e com a cultura na constituição do psiquismo, mas o tratamento é, via de regra, dirigido para o âmbito de uma dinâmica intrapsíquica.

Vasconcelos (2009, p. 44) corrobora esta idéia quando discute as características hegemônicas do modelo clínico liberal: "ênfase no atendimento individual,(...) elaboração psicológica sustentada nos 
códigos culturais e linguísticos das elites letradas da sociedade (...) e foco praticamente exclusivo nos processos psíquicos".

\subsection{Cenário 3: da psicologia em movimento}

Uma parte da psicologia, por sua vez, movimenta-se para fora, um movimento ex-cêntrico e ek-stático, atendendo à exigência de recomeço e percebendo que o risco de reduzir o sofrimento ao intrapsíquico é de transformar o espaço da psicoterapia em outra forma de sofrimento. Diálogos e movimentos interdisciplinares apontam uma tendência não-psicologizante, que não considera possível, tampouco suficiente, uma psicologia sem sociologia, antropologia, história, ciência política.

Há um descompasso entre a demanda instrumental que se faz à Psicologia e esse projeto em progressão. Para compreender e superar isso por meio de novas instituições de sentido para a práxis da clínica, faz-se necessário, entre outras coisas, refletir sobre o momento histórico da passagem do século XX ao século XXI. Já se foi a primeira década do novo século. A crise do capitalismo globalizado nos põe diante de um novo estado de coisas. Diante dos desafios que representam as novas (e reedições das velhas) formas de relações, subjetivação e sofrimento no mundo contemporâneo, a psicologia clínica tem sido convocada a repensar seu projeto (BIRMAN, 1999; FONSECA; ENGELMAN, 2004; ANDRADE; MORATO, 2004; DUTRA, 2004; COSTA; BRANDÃO, 2005; ALVIM, 2009).

Muito se tem discutido sobre o tema e sobre a necessidade de pensar modelos clínicos ampliados na psicologia. Algumas propostas centram-se no corpo e nos afetos. Franco e Galavote (2010) fazem referência a algumas delas: A Clínica Ampliada (CAMPOS; AMARAL, 2007; CUNHA, 2005); Clínica Peripatética (LANCETTI, 2006); Clínica do Desvio - Klinamen (BENEVIDES; PASSOS, 2001), Clínica do CsO (MERHY, 2007). De acordo com os autores essas são algumas das sugestões de um amplo mosaico de propostas que têm por objetivo não apenas a discussão, mas, sobretudo, uma práxis voltada para o cuidado em saúde. Os autores propõem a Clínica dos Afetos: "Pensamos assim que a clínica do olhar deve compor com a dos afetos operando sobre as diversas dimensões do corpo e produzindo ao mesmo tempo a intervenção sobre os órgãos, e um processo intenso de subjetivação pelos afetos" (FRANCO; GALAVOTE, 2010).

\subsection{Cenário 4: da Gestalt-terapia}

$\mathrm{Na}$ formulação da Gestalt-terapia que nasce em 1951 houve a colaboração de um grupo de pensadores de diversas disciplinas: psicanálise, psicologia da gestalt, sociologia, estudos orientais, medicina, educação. Inaugura-se na psicologia um pensamento que 
considera o campo organismo/ambiente o ponto de partida e o foco da psicoterapia. Dirigidos pelo interesse e foco na estrutura organismo-ambiente, esse grupo formulou compreensões que abrangiam e enfatizavam o embate entre as forças sociais e 0 movimento centrífugo do organismo em direção à regulação.

\begin{abstract}
Em toda e qualquer investigação biológica, psicológica ou sociológica temos de partir da interação entre o organismo e seu ambiente. Não tem sentido falar, por exemplo, de um animal que respira sem considerar o ar e o oxigênio como parte da definição deste (...). O significado da raiva compreende um obstáculo frustrante; o significado do raciocínio compreende problemas de prática. Denominemos esse interagir entre organismo e ambiente em qualquer função o 'campo organismo/ambiente', e lembremo-nos de que qualquer que seja a maneira pela qual teorizamos sobre impulsos, instintos etc., estamos nos referindo sempre a esse campo interacional e não a um animal isolado (PERLS; HEFFERLINE; GOODMAN, 1997, p. 42).
\end{abstract}

Quando dizemos que self é contato, que nos fazemos e refazemos a partir do campo organismo ambiente, estamos considerando não um sujeito psíquico, mas uma totalidade estrutural com dimensões "sócio-culturais, animais e físicas" (PERLS; HEFFERLINE; GOODMAN, 1997). O que equivale às três ordens da estrutura, tal como proposto por Merleau-Ponty: ordem física, vital e humana ou simbólica.

Se falamos de um campo sócio-cultural, animal e físico a partir do qual há produção de um ajustamento criador, podemos tomar como referência a idéia de que o que faço (espontaneidade motora) tem uma dimensão de ajustamento e outra de criação alimentadas por uma dimensão física (materialidade) outra animal (vitalidade, instintos, pulsões ou hábitos?) e outra sócio-cultural (capacidade simbólica, representações, ideais sociais, crenças, moral) entrelaçadas de modo complexo. Está em jogo uma proposta de psicoterapia fundada na complexa imbricação de natureza e cultura. Quando propõe que no processo de contato o sistema self de contatos funciona no modo médio, indica uma posição filosófica e epistemológica que postula - encontrando-se com as propostas de Merleau-Ponty-, que a produção de sentidos seja instituição, noção que implica o surgimento de algo que referenciará experiências ulteriores. Ao contrário de um sentido que surge da minha interioridade ou subjetividade como constituição, a instituição é um sentido que me aparece por meio de uma situação - tempo-espacial - que produz um movimento, apela ao futuro, ao porvir. "O tempo é - modelo da instituição: passividade-atividade, ele continua" (MERLEAU-PONTY, 2003, p. 5). A partir de seu aspecto universalizante, continua o filósofo, instituição são "eventos-matrizes, abertura de um campo histórico que tem unidade" (op.cit., p.44). 
O método clínico da Gestalt-Terapia se desenvolveu em torno do contato como movimento de desdobramento temporal - ajustamento criador diante da diferença. Como discutimos, visa, partindo da situação psicoterápica, ampliar a capacidade de awareness (sentir, excitamento e formação de gestalten) propondo abertura e entrega ao campo (sentir) para que o excitamento flua de acordo com o campo ou situação de interação (forças presentes), haja um trabalho criador e instituinte que permita a formação de gestalten no campo.

\begin{abstract}
$\mathrm{Na}$ perspectiva da gestalt-terapia, não somos frutos de determinações externas ou sociais, tampouco de determinações psíquicas, mas nos fazemos e refazemos a partir do campo organismo-ambiente, imbricados no mundo com as coisas e os outros, sendo parte de situações concretas e sócio-históricas. É a partir dessa condição situada e intersubjetiva que criamos sentidos, significamos e ressignificamos nossa existência e o mundo (ALVIM, 2010).
\end{abstract}

Importa-nos aqui ressaltar que a Gestalt-Terapia visa à totalidade organismo-ambiente, concebendo um eu que se faz e refaz na relação. Visa o corpo e o encontro com a necessidade mais genuína naquele campo, parte da singularidade expressa naquela situação, garantindo a possibilidade da diferença.

Ao pensar em uma clínica poiética, pretendemos provocar um diálogo, um deslocamento e a busca de novos sentidos. Queremos dizer com isso que buscamos um pensar sobre a clínica que não se restrinja à gestalt-terapia, tampouco ao espaço do consultório ou à clínica tradicional. Que não seja disciplinar na própria psicologia. Que assuma a noção de clínica como Klinamen, ou seja, desvio de direção. Que se possa expandir para as comunidades humanas em todas as suas dimensões e singularidades.

\title{
4 Elementos para uma clínica poiética
}

Para o desenvolvimento da proposta de uma clínica como poiética aqui delineada, coloca-se como requisito e fundamento encará-la como ethos - tal como significava na Grécia antiga a natureza - lugar de acolhida, morada, abrigo, onde nos sintamos con-fiantes diante do outro diferente e a ele unidos por uma aisthesis, dada na experiência da intercorporeidade, ou seja, do "sentir com" (ALVIM, 2011). Colocam-se então algumas dimensões elementares para nossa proposta:

1- a proposta de escrever à margem visa, na dimensão ethos da clínica, à abertura de espaço, acolhimento que se faz primeiro no esvaziamento dos sentidos para que, daí, seja exigida a experiência da criação e de ser; 
2- a tomada do corpo como sentir e co-presença permite a experiência do "eu posso"; a experiência do outro é uma operação empática corporal e sensível que permite a completude de uma consciência de ser aqui-agora.

3- O corpo como sentir e co-presença permite, na experiência empática da aisthesis, uma segunda abertura de espaço para a experiência do "eu posso";

4- o poder do "eu posso" não é um poder constituinte, mas instituinte, ou seja,

a instituição oferece um sentido alargado para o que Merleau-Ponty denominou "eu posso" na fenomenologia da percepção: "relação com o espaço-tempo valorados, em suma, como capacidade para o novo, o genérico, o particular e o universal. Donde a insistência de Merleau-Ponty de que o modo de ser da instituição não é o de um fazer eficaz ou eficiente fundado numa relação entre meios e fins e numa escolha, mas é uma operação simbólica ou um ato, que pode ser designado como nascimento, entendido como instituição de um porvir (Chauí, 2009, p.31).

5- Trata-se de uma práxis que permita o nascimento espontâneo do sentido como instituição - atividade que ao mesmo tempo retoma o passado e exige um futuro -, fala que uma vez proferida se faz ser, criatura, presença inexorável que, sedimentada na história e na cultura, nos garante o pertencimento com o outro a um mesmo mundo.

O apelo ao poiético que aqui fazemos nos dá a pensar o terapeuta como aquele que instiga a fala falante. $O$ que remete à diferença. É com esse horizonte que tomamos a noção de "desajustamento criador" (Alvim, 2007), como um tipo de intervenção psicoterápica que visa introduzir na situação uma novidade que lance terapeuta e participante ao âmbito do invisível, ao espaço deserto das representações, ao vazio fértil de significações. É diante do vazio que se vislumbra adiante a possibilidade, quando se vive a experiência do "eu posso", vivência que alimenta a ação criadora e transgressora. O vazio aqui discutido não tem significado psicológico, não é uma falta nesse sentido. Como propõe Dupond (2010) a partir de MerleauPonty, "são ocos que se produzem quando se deslocam as discrepâncias de significado" (p.31).

As tarefas do desajustamento criador se inspiram na arte moderna: descentrar o olho e desnaturalizar a percepção. Descentrar o olho que é sempre seduzido pelas facilidades da paisagem conhecida, da imagem fotográfica, como disse Merleau-Ponty. As representações e teses científicas podem ser uma bela e sedutora paisagem, entretanto, fixam o nosso olhar, impedem o exercício da crítica, fazem adormecer o corpo e os sentidos. Desnaturalizar a percepção é convidar ao trabalho perceptivo, passar ao terreno do desconhecido, 
do imprevisível que, partindo das entranhas da carne, nos obriga a um engajamento no mundo para significá-lo. Inspirados nos movimentos de vanguarda da arte moderna, fizemos, naquele trabalho (Alvim, 2007), uma imagem metafórica do terapeuta como um personagem daquela vanguarda, que aqui retomamos.

Consideramos o terapeuta um moderno inveterado. "Educador" dos sentidos para que se produza o novo, o diferente, a fala falante, sua música, às vezes, é atonal e provoca desagrado. Seu trabalho envolve a dimensão satânica da experiência e da reorganização da percepção. É aquele que busca o descentramento como forma de afirmar a existência. Karl (1998, p. 18) adverte que o satânico da experiência tende a ser associado à decadência e à podridão. Acreditamos, ao contrário, que a demonização é um processo belo e vital. A ação de produção do contraditório a partir do desajustamento criador aciona os sentidos, a corporeidade e remete à experiência estética. Ao considerar o espaço da psicoterapia como um campo de experiência, espaço expressivo e instaurador de significados, estamos no âmbito da experiência estética. Transformar a existência em objeto estético significa reconciliar o autor com sua própria obra, que agora pode ser vista em outra perspectiva, permitindo criação e reconciliação com si mesmo no mundo. Até mesmo - e quase sempre o é - quando essa reconciliação é transgressora: provoca choques e transgride o que está dado.

O sentido ético de tal postura clínica

O desajustamento criador propõe a frustração do modo fixado de realizar a experiência e o suporte para a criação de novos modos de experienciar o contato. Se o terapeuta trabalha nessa perspectiva, está implicado na situação e então precisa, ele próprio, saber enfrentar 0 sertão desconhecido, ajustar-se criativamente às novidades, abrir mão do controle. De acordo com seu estilo, saberá o melhor modo de experimentar a experimentação. De acordo com cada cliente, em cada situação.

Sem perder-se de vista, sem sair, ele próprio, da situação buscando segurança neurótica na técnica. O grande mal acontece quando a situação terapêutica representa, para o terapeuta, um "estado de emergência crônico de baixo grau" (PERLS; HEFFERLINE; GOODMAN, 2007, p. 123). Então ele poderá tender à busca de uma falsa segurança. Miller (2002) define comprometimento como ficar com a experiência presente. Para ele, isso transcende um princípio técnico ou um método, mas é "princípio estético de transformação" e "posição ética" (p. 113).

Corroboro sua posição, pois penso que quando a Gestalt-Terapia propõe ficar com a experiência e com a expressão singular do cliente, ela assume uma posição ética oferecendo o espaço do ser e da experiência do outro. Tal posição é também corajosa: ao mesmo tempo em que 0 terapeuta deseja que o cliente vivencie sua 
espontaneidade e se abra criativamente para a novidade e o desconhecido, ele próprio abre mão do "controle" da situação, se lançando também para o âmbito do desconhecido.

\section{Considerações Finais}

Ao discutir o contra-efeito que o artista moderno amarga ao exercer seu papel de vanguarda, Karl (1998) faz referência ao incômodo do grande público com a música de Schoenberg: "A inclinação do público favorecia claramente o neoclassicismo de Stravinsky, assimilável, e se manifestava contra a atonalidade e os 12 tons de Schoenberg, inaceitáveis para os ouvidos" (p. 18).

Os contra-efeitos que atingem nossa imagem diante do grande público são uma questão essencial para pensarmos na psicologia contemporânea e na demanda que a ela é dirigida. Os riscos da psicologia psicologizante, da demanda instrumental feita a ela, se colocam também para nós, que comungamos perspectivas existenciais e fenomenológicas em psicologia. Para escapar de uma psicologia psicologizante, de uma demanda instrumental, precisamos da crítica permanente. A complexidade das forças políticas, dada pelas transformações do modo de produção capitalista, requer do terapeuta uma capacidade crítica da cultura e da sociedade, assim como de sua própria práxis. Nesta perspectiva, se faz indispensável uma postura à margem e que sustente os contra-efeitos. Faz-se igualmente necessário um diálogo interdisciplinar que possa propiciar práticas transdisciplinares, um movimento que avance do paradigma da simplicidade, tal como propõe Edgar Morin e que possa avançar para a complexidade, retomando os primórdios de uma prática clínica ainda não atingida pela miopia da especialização. Para lidar com algumas forças invisíveis, instituições e sedimentações do mundo contemporâneo que agem como forças agenciadoras de subjetividade (GUATTARI, 1992) é preciso levar a noção de situação às últimas consequências, nos perguntando até que ponto, permanecendo fechados em nossos consultórios e abordagens, concreta ou metaforicamente falando, temos condições de integrar em nosso diálogo movimentos vibrantes que, como navalha na carne, possam instituir.

Na vida midiática do ano de 2011 o mesmo jogo de imagens que nos mata em série, nos atinge em dois flancos: de um lado com a arte viva e transgressora de uma Amy Whinehouse (que poderia ser Janis Joplin, Cássia Eller, Elis Regina) nos sentimos inspirados e confirmados em nossa dimensão poiética. De outro, sua morte trágica reafirma, de modo novo, o heroísmo de Cara de cavalo, quando lança no mundo, como instituição, um grito da dor pungente de todos nós, dimensão universal e invisível, carne do mundo atravessada e 
sangrando, exigindo, implorando por novas criações de sentido que possam retomar e ecoar sentidos para a vida.

Apelo que brota da angústia, a po-ética na clínica consiste em nascimento, gênese do sentido como fala falante e desviante. Com um movimento de zigue-zague, a clínica não anda em linha reta, nem concebe cada um andando na sua linha, mas, ao contrário, é copresença e co-afetação que institui e garante o pertencimento a um mesmo mundo. A po-ética é, assim, força mobilizadora que, diante do abismo, nos impulsiona à aventura de voar.

\section{Referências}

ALVIM, M. B. Ato artístico e ato psicoterápico como Experimentação: diálogos entre a fenomenologia de Merleau-Ponty, a arte de Lygia Clark e a Gestalt-Terapia. 2007. 374f. Tese (doutorado em Psicologia) - Instituto de Psicologia, Universidade de Brasília, Brasília. A clinica da gestalt-terapia: experiência e criação. Mosaico, Belo Horizonte, v. 4, n. 1, p. 66-69, 2010. Disponível em: <http://www.fafich.ufmg.br/mosaico>. Acesso em: 10.10.2011

Desafios para a psicoterapia diante dos dilemas da contemporaneidade: a diferença, 0 público e $o$ privado. Comunicação oral no CONPSI - $6^{\circ}$ Congresso Norte-nordeste de Psicologia. Belém, 2009.

. A ontologia da carne em merleau-ponty e a situação clínica na gestalt-terapia: entrelaçamentos. Revista da Abordagem Gestáltica. Volume XVII, N. 2, Pp.143-151, Jul/Dez, 2011.

ANDRADE, A. N.; MORATO, H. T. P. M. A dimensão ética (e moral) das práticas institucionais. Revista Estudos de Psicologia UFRN, Natal, v. 9, n. 2, p. 345-353, 2004..

BIRMAN, J. Mal-estar na atualidade: a psicanálise e as novas formas de subjetivação. Rio de Janeiro: Civilização Brasileira, 1999.

CHAUÍ, M. S. (2009) Merleau-Ponty: da Constituição à Instituição. Cadernos Espinosanos / Estudos Sobre o século XVII, Sâo Paulo, n. 20, jan-jun 2009.

COSTA, L. F.; BRANDÃO, S. N. Abordagem clínica no contexto comunitário: uma perspectiva integradora. Psicologia \& Sociedade (online), v. 17, n. 2, p. 34-41, 2005. Disponível em: <http://www.scielo.br>. Acesso em: 20 jul. 2008.

DUPOND, P. Vocabulário de Merleau-Ponty. São Paulo: Ed. Martins Fontes, 2010.

DUTRA, E. Considerações sobre as significações da psicologia clínica na contemporaneidade. Estudos de Psicologia, Natal, v. 9, n. 2, p. 381-387, 2004. 
FONSECA, T. M. G.; ENGELMAN, S. Corpo, arte e clínica. Porto Alegre: Ed. da UFRGS, 2004.

FRANCO, T. B.; GALAVOTE, H. S. Em Busca da Clínica dos Afetos. In: FRANCO, T. B.; RAMOS, V. C. Semiótica, afecção e cuidado em saúde. Hucitec, São Paulo, 2010.

GUATTARI, F. Caosmose: um novo paradigma estético. Rio de Janeiro: Editora 34, 1992

KARL, F. R. O moderno e o modernismo: a soberania do artista 1885-1925. Rio de Janeiro: Imago Editora, 1988.

MERLEAU-PONTY, M. Fenomenologia da percepção. São Paulo: Martins Fontes, 1994.

2000.

. O visível e o invisível. São Paulo: Editora Perspectiva,

A natureza. São Paulo: Martins Fontes, 2000n.

Lìnstitution, la passivité: notes de cours au college de France (1954-1955). Paris:Editions Belin, 2003.

MILLER, M. V. The aesthetics of commitment: what gestalt therapists can learn from Cezanne and Miles Davis. The Gestalt Journal, New York, v. 25, n. 1, p. 109-122, 2002.

MÜLLER, M. J. Merleau-Ponty acerca da expressão. Porto Alegre: Edipucrs, 2001.

OITICICA, H. Aspiro ao grande labirinto. Rio de Janeiro: Rocco, 1986.

PERLS, F.; HEFFERLINE, R.; GOODMAN, P. Gestalt-terapia. São Paulo: Summus Ed., 1997.

PERLS, L. Living at the boundary. New York: The Gestalt Journal Press, 1992.

ROBINE, J. M. O self desdobrado. São Paulo: Summus Ed., 2006 VASCONCELOS, E. M. Abordagens Psicossociais, v.1:história, teoria e prática no campo. 2.ed. Ed. Hucitec, São Paulo, 2009.

\section{Endereço para correspondência}

Mônica Botelho Alvim

Av. Pasteur, 250 - Pavilhão Nilton Campos. Campus da Praia Vermelha,

Cep. 22.290-240, Rio de Janeiro - RJ, Brasil

Endereço eletrônico: mbalvim@gmail.com

Recebido em: 09/11/2011

Aceito para publicação em: 11/10/2012

Acompanhamento do processo editorial: Ana Maria Lopes Calvo de Feijoo

\section{Notas}

*Doutora em Psicologia - Universidade de Brasília - UnB.

${ }^{1}$ Artista brasileira que fez parte do movimento neoconcreto no Rio de Janeiro (1959) e que exerceu um papel importante na formulação de concepções instituintes para a arte contemporânea, como a participação do espectador e a implicação do corpo do espaço da arte. 
${ }^{2} O$ termo é utilizado na Gestalt-Terapia para indicar um tipo de relação sujeitomundo que funciona em um modo médio, ou seja, nem ativo, nem passivo. Provém da lingüística, de um modo verbal médio que desapareceu da maior parte das línguas, onde sobrevivem apenas os modos verbais ativo e passivo. Ver Perls, Hefferline e Goodman (1997), Robine (2006) e Alvim (2007). 